\title{
TITLE:
}

\section{$<$ Note> Assessment of the planted trees in Green Corridor Project}

\author{
$\operatorname{AUTHOR}(S)$ :
}

Matsuzawa, Tetsuro

\section{CITATION:}

Matsuzawa, Tetsuro. < Note> Assessment of the planted trees in Green Corridor Project. Pan Africa News 2007, 14(2): $27-29$

ISSUE DATE:

2007-12

URL:

http://hdl.handle.net/2433/143481

\section{RIGHT:}

Copyright (C) Pan Africa News. 


\title{
$<$ NOTE $>$
}

\section{Assessment of the planted trees in Green Corridor Project}

\author{
Tetsuro Matsuzawa \\ Primate Research Institute, Kyoto University, Japan
}

The Bossou chimpanzees were first described by French and Dutch scientists ${ }^{4,5}$. Since 1976, Japanese scientists and then an international team (KUPRI-International) have been studying the chimpanzees at Bossou ${ }^{6,9}$. The community is at present isolated from the neighboring groups in the Nimba Mountains. In 1982, Sugiyama noted the arrival of a single immigrant male to Bossou, yet no comparable additions to the group have been observed since. The number of chimpanzees in Bossou has been stable, about 20, for the last 3 decades $^{8}$. However, the number suddenly decreased to 13 (as of September 2007), mainly 
due to the death caused by an epidemic respiratory disease in the November of $2003^{7}$. We can therefore infer the potentiality for serious genetic problems arising in the near future. For the future of the Bossou community, it is necessary to promote the reforestation of corridors connecting the neighboring communities.

The nearest community of chimpanzees lives in the Nimba Mountains, at a distance of approximately $10 \mathrm{~km}$ from the center of Bossou to the ridge. Savanna vegetation extends along a radius of at least $4 \mathrm{~km}$ between Bossou and Seringbara, the nearest area in the Nimba Mountains, where we identified at least one community of chimpanzees ${ }^{2,3}$. In January 1997, the Japanese researchers in collaboration with the local Manon people started creating "Green Corridor (Corridor Vert)" by planting trees in the savanna area along a $300 \mathrm{~m}$ wide $4 \mathrm{~km}$ long stretch of land extending between Bossou to Seringbara. The corridor should promote the migration between the two groups.

The initial effort was to create a small botanical garden (Projet Petite Jardin), as a pilot attempt of the Green Corridor Project. The garden was constructed on 0.36 ha $(60 \mathrm{~m} \times 60 \mathrm{~m})$ in the peripheral savanna area of chimpanzee habitat. We first cut back poaecous plant species and then planted nursery trees from 28 species, all of which can be found in the core area of the chimpanzees' habitat of Bossou ${ }^{10,11}$. The total number of the trees planted was 250 . One and half years later, in July, 1998, the trees in the garden were inspected and the number of live trees had decreased to 125 , which means that $50 \%$ of the planted trees had survived ${ }^{1}$.

In January 2005, a second inspection was carried out 8 years after initiation of the project. During the 8 years, there was no further attempt to planting trees in that same plot. In the assessment, the number of surviving trees had decreased to 62 , which means that based on the initial number of planted trees $25 \%$ had survived. We identified 9 species that survived in the savanna during the course of the 8 years (Table 1). Among them, the most successful ones were Uapaca heudelotii, and then Parkia bicolor. The tallest chimpanzees' feeding.

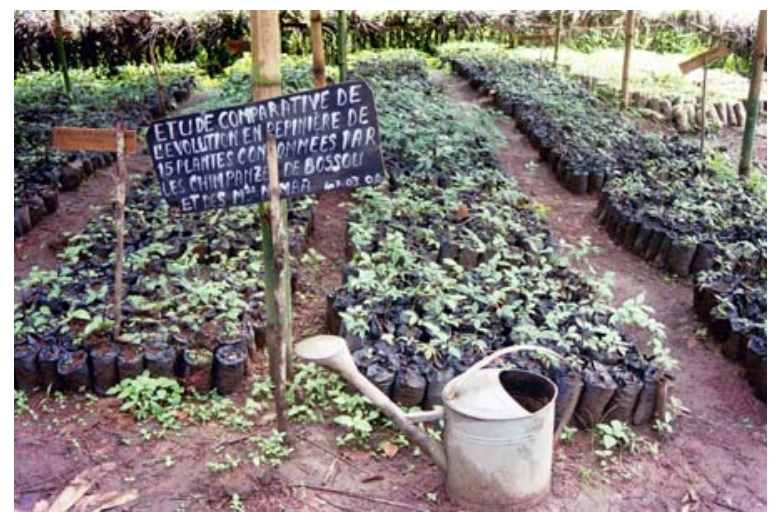

Fig. 1 Young trees were grown in the tree nursery, where each sapling was kept in a plastic sac. Green Corridor Project established an unique way of utilizing chimpanzee faeces to grow the samplings. Photo by $T$. Humle.

tree was a tree of Parkia bicolor (\#PJ-48), $9.3 \mathrm{~m}$ in height, $3.8 \mathrm{~cm}$ in $\mathrm{DBH}$, and $5 \mathrm{~m}$ in radius. The second tallest tree was a tree of Uapaca heudelotii (\#PJ-30), $9.2 \mathrm{~m}$ in height, $12.7 \mathrm{~cm}$ in $\mathrm{DBH}$, and $5 \mathrm{~m}$ in radius.

In addition to the planted trees, we counted the total number of trees taller than $30 \mathrm{~cm}$ to find another 386 trees and saplings that had not been planted by us. These trees had grown naturally in the plot: The seeds were most likely brought by the wind, animals, and/or birds. In total, after 8 years, there were 448 trees and saplings present in this plot. This means that $86.2 \%$ of the trees and saplings had resulted from a natural regeneration process during this period. Among the naturally grown trees and saplings, we identified 30 species, a high diversity of tree species in such a small surface area. Among them, the following three species were dominant: Harungana madagascariensis $(\mathrm{n}=55)$, Nauclea latifolia $(\mathrm{n}=55)$, Dychrostachys glomerata $(n=40)$. These species are pioneer tree species.

Since our initial efforts 8 years ago, we can make

Table 1 Tree species that survived in the savanna.

\begin{tabular}{llllll}
\hline Scientific name & Family & Manon name & Type & Part & No. Trees \\
\hline Uapaca heudelotii & Euphorbiaceae & Sonna & F & Fr & 35 \\
Parkia bicolor & Mimosaceae & Komi & Fs,Fd & Fr & 9 \\
Craterispermun codatum & Rubiaceae & Gbeke-guan & Fs & Ec & 5 \\
Craterispermun laurinum & Rubiaceae & Gbeke & Fs & Ec & 3 \\
Albizia zygia & Mimosaceae & Kpaan-tii & Fs & Gm,Fl & 6 \\
Blighia welwitschii & Sapindaceae & Glain-puru & F & Fr & 1 \\
Spondias mombin & Anacardiaceae & Buna & Fs & Fr & 1 \\
Vismia guineensis & Hypericaceae & Bla-loro & Fs & na & 1 \\
Vitex oxypiscus & Berbenaceae & Bom & F & Fr & 1
\end{tabular}

Notes: Type: Vegetation type, F:Forest, Fs: Secondary and deciduous forest, Fd: Dense forest, Part: The plant part consumed by the chimpanzees, Fr: Fruit, Fl: Flower, EC: Bark, Gm: Gum or resin, na: No record of 
the following three conclusions. First, some forest tree species, such as Uapaca heudelotii, and Parkia bicolor, can survive well when planted in the savanna. This evaluation of the Petit Jardin project has helped us select those tree species for future transplantation that both provide food for the chimpanzees and can thrive in the savanna. Second, we noted a significant natural regeneration process in our pilot savanna plot, which suggests that protecting the area from browsing animals and preventing bush fires can by themselves generate a greater diversity and density of tree species than transplanting nursery grown trees alone (We had the bush fires at least three times in the past 10 years, and the last one in February 2007 gave the serious damage on the corridor as a whole). These supplementary activities are therefore crucial for the success of reforestation programs in savanna areas. Third, we found that we can transform the savanna into forest through a reforestation program. Based on our initial attempt in the Petit Jardin, we estimate that in 8 years, we can grow trees reaching close to $10 \mathrm{~m}$ in height using our method of growing trees in a nursery and transplanting the young trees to the savanna.

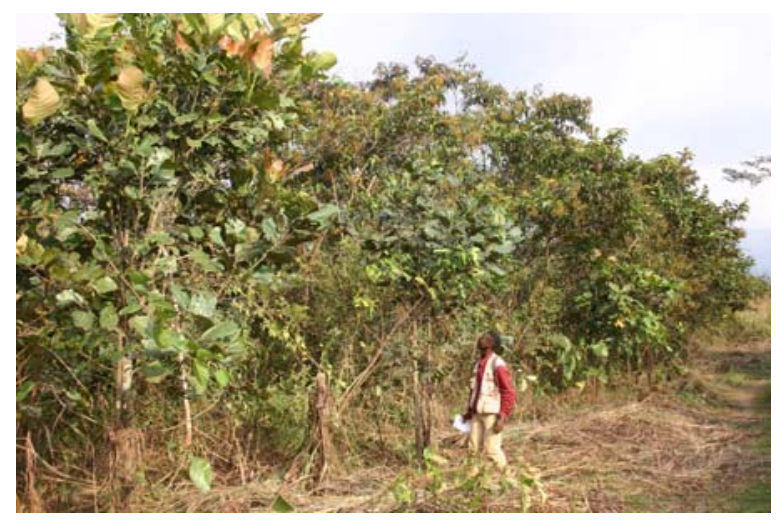

Fig. 2 The savanna was transformed to a secondary forest. You can still recognize the planted Uapaca heudelotii trees placed at $5 \mathrm{~m}$ interval. Photo by $\mathrm{T}$. Matsuzawa.

Acknowledgments. This work was financially supported by MEXT-07102010, 12002009, and 16002001 and JSPS-HOPE to the author. The current project is supported by Japan Ministry of Environment Global Environment Research Fund (\#F-061) to Dr. Toshisada Nishida. Thanks are due to the colleagues on site who made the initial efforts of planting trees such as Guano Goumy, Tino Zogbila, and Jeremy Koman. I also thank the research assistants for the assessment of the Petit Jardin Project such as Paquile Cherif and Soh Pleta Bonimy. Thanks are also due to the Guinean authorities, Dr. Makan Kourouma in IREB and Drs. Kabine Kante and Tamba Tagbino in DNRST. I am also grateful for the effort of colleagues who contributed this project in each stage; Yukimaru Sugiyama, Gen Yamakoshi, Tatyana Humle, Gaku Ohashi, Nicolas Granier, and Ryo Hasegawa.

\section{REFERENCES}

1. Hirata S, Morimura N, Matsuzawa T 1998. Green passage plan (tree-planting project) and environmental education using documentary videos at Bossou: A progress report. Pan Afr News 5: $18-20$.

2. Humle T, Matsuzawa T 2004. Oil palm use by adjacent communities of chimpanzees at Bossou and Nimba Mountains, West Africa. Int J Primatol 25: 551-581.

3. Koops K, Humle T, Sterck EHM, Matsuzawa T 2007. Ground-nesting by the chimpanzees of the Nimba Mountains, Guinea: environmentally or socially determined? Am J Primatol 69: 407-419.

4. Kortlandt A 1986. The use of stone tools by wild-living chimpanzees and earliest hominids. J Hum Evol 15: 77-132.

5. Lamotte M 1942. La faune mammalogique du Mont Nimba (Haute Guinée). Mammalia 6: 114-119.

6. Matsuzawa T 2006. Bossou 30 ans. Pan Afr News 13: 16-19.

7. Matsuzawa $\mathrm{T}$ 2006. Sociocognitive Development in Chimpanzees: A Synthesis of Laboratory Work and Fieldwork. In: Cognitive Development in Chimpanzees, Matsuzawa T, Tomonaga M, Tanaka M (eds), Springer, Tokyo, pp.3-33.

8. Sugiyama Y 2004. Demographic parameters and life history of chimpanzees at Bossou, Guinea. Am J Phys Anthropol 124: 154-165.

9. Sugiyama Y, Koman J 1979. Social structure and dynamics of wild chimpanzees at Bossou, Guinea. Primates 20: 323-339.

10. Sugiyama Y, Koman J 1987. A preliminary list of chimpanzees alimentation at Bossou, Guinea. Primates 28: 133-147.

11. Sugiyama Y, Koman J 1992. The flora of Bossou: It's utilization by list of chimpanzees and humans. Afr Study Monogr $13,127-169$. 